\title{
LEVANTAMENTO E ANÁLISE COMPARATIVA DOS PADRÕES DE DRENAGEM DAS BACIAS HIDROGRÁFICAS DOS RIOS AGUAPEÍ E PEIXE
}

\author{
JhonatanLaszloManoel $^{(\mathrm{a})}$, Paulo Cesar Rocha ${ }^{(\mathrm{b})}$ \\ (a) Universidade Estadual Paulista Julio de Mesquita Filho - Faculdade de Ciência e Tecnologia, \\ jho896@hotmail.com \\ (b) Universidade Estadual Paulista Julio de Mesquita Filho - Faculdade de Ciência e Tecnologia, \\ pcrocha@fct.unesp.br
}

\section{EIXO: BACIAS HIDROGRÁFICAS E RECURSOS HÍDRICOS: ANÁLISE, PLANEJAMENTO E GESTÃO}

\begin{abstract}
Resumo
Os padrões de drenagens representam um dos principais parâmetros morfométricos a serem averiguados, para justificar a forma da distribuição espacial dos canais fluviais em uma bacia hidrográfica. Os padrões de drenagens das Bacias Hidrográficas dos Rios Aguapeí e Peixe foram gerados através da identificação visual dos cursos d'águas nelas inseridas, os quais foram vetorizados e classificados de acordo com a sua distribuição espacial, sendo gerada uma carta dos padrões identificados. Sobre os resultados identificados, verificou-se que há uma distribuição predominante do padrão de drenagem do tipo dendrítico pela predominância das rochas da Formação Adamantina do Grupo Bauru, mas também foram identificados padrões sub-dendríticos e paralelos, sendoque o último apresenta-se pela forte inclinação do relevo. Por fim, alguns cursos d'água ficaram sem classificação por não possuir canais confluentes e não demonstrar configuração genética, com apenas um canal retilíneo.
\end{abstract}

Palavras-Chave: Padrões de Drenagem, Bacia Hidrográfica, Rio Aguapeí, Rio do Peixe.

\section{Introdução}

O levantamento das características de uma bacia hidrográfica é um dos primeiros e mais comuns métodos a serem realizados em análises hidrológicas ou ambientais, e tem como objetivo esclarecer as várias questões relacionadas com o entendimento da dinâmica ambiental de uma determinada bacia hidrográfica.

Os padrões de drenagem,escopo deste trabalho, apresentam-se em função do tipo de rocha e das estruturas geológicas presentes numa determinada área, sendo assim, composta por um conjunto de canais de escoamento que são influenciados por atividades morfogenéticas, de acordo com a disposição das camadas rochosas, pela resistência litológica variável e também pelo estágio evolutivo do relevo.

A drenagem fluvial é constituída por um conjunto de canais de escoamento interligados. A área drenada por esse sistema fluvial é definida como bacia de drenagem, depende não só do 


\section{OS DESAFIOS DA GEOGRAFIA FÍSICA NA FRONTEIRA DO CONHECIMENTO \\ Instituto de Geociências - Unicamp \\ Campinas - SP \\ 28 de Junho à 02 de Julho de 2017}

total, mas também do regime das precipitações, bem como das perdas por evapotranspiração e infiltração. Tem papel importante no escoamento canalizado a topografia, a cobertura vegetal, o tipo de solo, a litologia e a estrutura das rochas da bacia hidrográfica. A disposição espacial dos rios, controlada em grande parte pela estrutura geológica, é definida como padrão de drenagem. (Howard,1967, apud CUNHA, 2001 in CUNHA \& GUERRA, 2001, p. 225)

A noção da declividade de uma bacia hidrográfica é considerada como um agente de grande preponderância sobre a velocidade do escoamento superficial, mostrando, portanto, o tempo que a água da chuva leva para concentrar-se nos leitos fluviais, e constituir uma rede de drenagem. Por fim, a organização espacial dos rios é influenciada e controlada pelas características morfológicas e estruturas geológicas da bacia hidrográfica, consolidando o tipo de padrão de drenagem e sua densidade na região de estudo.

Uma bacia hidrográfica pode englobar diferentes padrões geométricos para seus rios e uma gama de subtipos definidos em diversos trabalhos (Howard, 1967; Christofoletti, 1974; Sugio\&Bigarella, 1990, entre outros). Assim, como a padronagem geométrica relaciona-se com o ambiente geológico e climático local, é possível, através do estudo desses padrões, interpretar a natureza dos terrenos, a disposição das camadas alinhadas e das linhas de falhamento, os processos fluviais e climáticos predominantes. (CUNHA, 2001 in CUNHA \& GUERRA, 2001, p. 225).

Um fator muito importante a se destacar em estudos de geomorfologia é a influência das estruturas geológicas e litológicas de uma determinada área, ou no caso, de uma bacia hidrográfica. $\mathrm{O}$ conhecimento dos fatores endógenos de uma determinada área é de grande valia para o entendimento das formas e padrões encontrados na superfície terrestre, assim, a caracterização geológica (figura 4), mostra a alternância litológica existente dentro da área de estudo. 


\begin{tabular}{|c|c|c|}
\hline \multicolumn{3}{|l|}{ Fatores Internos } \\
\hline \multirow{2}{*}{ LITOLOGIA } & Parâmetros Físicos & $\begin{array}{l}\text { Presença ou não de cimento, porosidade, } \\
\text { permeabilidade, resposta à erosão, } \\
\text { competência e dureza. }\end{array}$ \\
\hline & Parâmetros Químicos & $\begin{array}{l}\text { Dissolução química da água subterrânea, } \\
\text { (re)cristalização e diagênese }\end{array}$ \\
\hline \multirow{3}{*}{ ESTRUTURA } & $\begin{array}{l}\text { Disposição das } \\
\text { Camadas }\end{array}$ & $\begin{array}{l}\text { Espessura das camadas, direção e } \\
\text { mergulho da camada, altemaçăo de } \\
\text { litologias, discordância e compactação } \\
\text { diferencial. }\end{array}$ \\
\hline & Neotectônica & $\begin{array}{l}\text { Movimentos horizontais e verticais, } \\
\text { vulcanismo e plutonismo, geodinâmica, } \\
\text { levantamento abaixamento, } \\
\text { subsidência, zona de deslocamento } \\
\text { horizontal, dobra, falha, juntas ou fratura, } \\
\text { e colocação de corpos magmáticos. }\end{array}$ \\
\hline & Tectônica & $\begin{array}{l}\text { Riftes, bacias, domos, áreas de vulcano- } \\
\text { plutonismo, discordância, dobras } \\
\text { (antiforme e sinforme), falhas e juntas. }\end{array}$ \\
\hline \multicolumn{3}{|l|}{ Fatores Externos } \\
\hline CLIMA & \multicolumn{2}{|c|}{$\begin{array}{l}\text { Precipitação (quantidade, tipo, estação, neve ou chuva), } \\
\text { temperatura (variação, estação) e paleoclima (glacial e periglacial) }\end{array}$} \\
\hline VEGETAÇĀO & \multicolumn{2}{|c|}{ Tipo, presença ou ausência e formação florestal. } \\
\hline HOMEM & \multicolumn{2}{|c|}{ Drenagem na, irrigação, canais, edificios estradas, etc. } \\
\hline \multicolumn{3}{|l|}{ Fatores Compostos } \\
\hline TOPOGRAFIA & \multicolumn{2}{|c|}{$\begin{array}{l}\text { Pendente regional e local, curva de nivel, paleotopografia e } \\
\text { paleossuperficie. }\end{array}$} \\
\hline VARIAÇÄO EUSTÁTICA & \multicolumn{2}{|c|}{ Erosão, sedimentação e nivel de base. } \\
\hline $\begin{array}{l}\text { FATORES } \\
\text { HIDROLÓGICOS }\end{array}$ & \multicolumn{2}{|c|}{ Padrão dos canais, vazão, carga e confluência. } \\
\hline HERANÇA & \multicolumn{2}{|c|}{$\begin{array}{l}\text { Padrão da paleodrenagem, outros tipos de talvegues (glacial, } \\
\text { oceânico), evolução da drenagem (superimposta, antecedente, } \\
\text { captura) }\end{array}$} \\
\hline
\end{tabular}

Figura 1 - Fatores morfológicos que afetam a evolução do padrão de drenagem.

Fonte: Deffontaines\&Chorowicz (1991) apud Lima (2006).

Desse modoa geologia caracteriza-se como agente causador das formas e dos padrões de drenagem dentro de uma bacia hidrográfica de maior importância, não sendo ignoradas as influências climáticas e antrópicas dentro deste sistema.Logo, este trabalho tem o intuito de levantar, analisar e comparar os padrões de drenagens das bacias hidrográficas dos Rios Aguapeí e Peixe, ressaltando as características espaciais identificadas.

\section{2. Área de estudo}

A região do extremo sudoeste do Estado de São Paulo, na qual estão localizadas as bacias dos Rios Peixe e Aguapeí caracteriza-se, segundo Nimer (1977), por um clima tropical quente e úmido (com chuvas de verão), e com um ou dois meses de estação seca (inverno). Próximo ao rio Paraná a umidade relativa do ar é maior.

Com base nos levantamentos apontados no Relatório zero do CBH-AP (1997), o substrato geológico aflorante nas Bacias dos rios Aguapeí e Peixe é constituído por rochas vulcânicas e sedimentares da Bacia do Paraná de idade mesozoica e depósitos aluvionares da idade cenozoica. Sua coluna estratigráfica apresenta respectivamente, da base para o topo, a seguinte sequência de formação geológica: Grupo São Bento - Formação Serra Geral, Grupo 
Bauru - Formações Caiuá, Santo Anastácio, Adamantina, Marília e Depósitos Cenozoicos. A geomorfologia das bacias dos rios Aguapeí e Peixeestá inserida na Província Geomorfológica denominada Planalto Ocidental. Os principais tipos de solos encontrados na região de forma mais expressiva são: Latossolo Vermelho, Argissolo Vermelho-Amarelo, Litólico, Planossolo, Gleissolo, Areias Quartzosas.

As bacias hidrográficas dos Rios Aguapeí e Peixe são caracterizadas pelo padrão de drenagem dendrítico (como pode ser visto na Figura 3) que é designada como arborescente, pois seu desenvolvimento assemelha-se à configuração de uma árvore. Observando essa imagem, a corrente principal corresponde ao tronco da árvore, os tributários aos seus ramos e as correntes de menor categoria aos raminhos e folhas. Da mesma maneira como nas árvores, os ramos formados pelas correntes tributárias distribuem-se em todas as direções sobre a superfície do terreno, e unem-se formando ângulos agudos de graduações variadas, porém nunca configurando um ângulo reto. A presença de confluências em ângulos retos, no padrão dendrítico, constitui anomalia que se deve atribuir, em geral, aos fenômenos tectônicos. Esse padrão é tipicamente desenvolvido sobre rochas de resistência uniforme, ou em estruturas sedimentares horizontais.

Os rios a serem estudados nesta pesquisa, caracterizam-se como rios conseqüentes ${ }^{1}$, que correm segundo a direção do mergulho das camadas geológico-geomorfológicas. Além disso, os rios principais, Aguapeí e Peixe, têm características que se assemelham a rios meandrantes em seu trecho aluvial. As nascentes e o alto curso desses rios apresentam-se como rios encaixados.

${ }^{1}$ Segundo Christofoletti (1980, p. 102-103)os rios seriam classificados como: consequentes, subsequentes, obsequentes, ressequentes, e insequentes. 
A

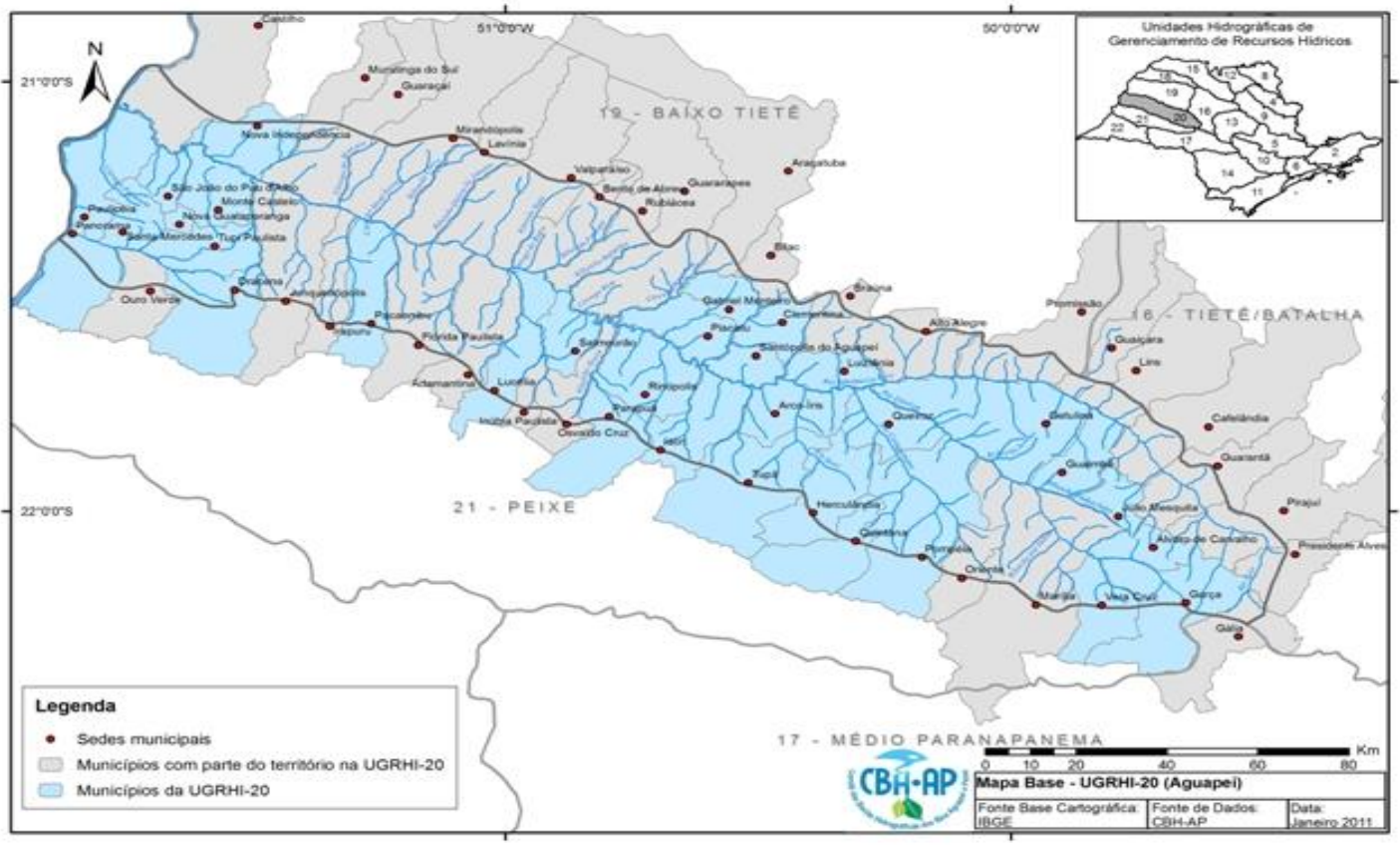

B

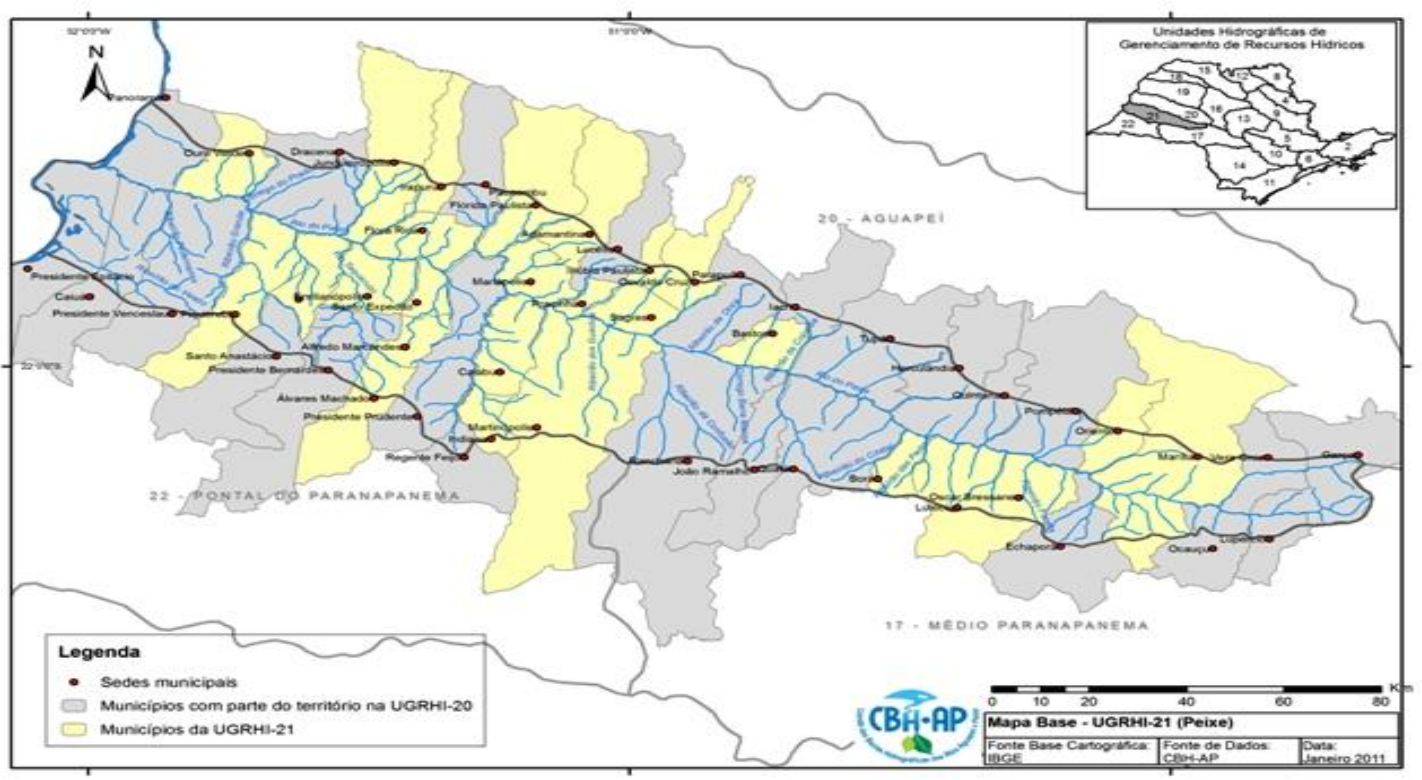

Figura 2 - UGRHI 20, Bacia do Rio Aguapeí A; UGRHI 21, Bacia do Rio Peixe B Fonte: CBH-AP

\section{Metodologia}

A escala utilizada nesse trabalho, foi de 1:250.000 tendo em vista que os mapas utilizados, tem suas bases cartográficas disponíveis no endereço digital do Comitê das Bacias Hidrográficas dos Rios Aguapeí e Peixe, no qual algumas delas já foram utilizadas e atualizadas em trabalhos anteriores e justamente pela dimensão da área a ser trabalhada. 
XVII Simpósio Brasileiro

de Geografia Fisica Aplicada

I Congresso Nacional

de Geografia Física

\section{OS DESAFIOS DA GEOGRAFIA FÍSICA NA FRONTEIRA DO CONHECIMENTO \\ Instituto de Geociências - Unicamp \\ Campinas - SP \\ 28 de Junho à 02 de Julho de 2017}

Para a elaboração dos padrões de drenagem das bacias e sub-bacias em estudo, foi realizada a identificação visual e vetorização de cartas topográficas e imagens de satélite do TOPODATA $^{2}$ do banco de dados geomorfométricos do Brasil. Após a identificação visual foramclassificadas e caracterizadas nos diferentes trechos das bacias hidrográficas em evidência neste trabalho. Por fim,foigerada uma carta dos padrões de drenagens encontrados nas bacias hidrográficas dos Rios Aguapeí e Peixe.

Desse modo, utiliza-se de Christofoletti (1974) que empregou um critério geométrico, da posição fluvial sem nenhum sentido genético, conceituando alguns tipos básicos de padrões de drenagem, designados como: a) drenagem dendrítica, b) drenagem treliça, c) drenagem retangular, d) drenagem radial, e) drenagem anelar e f) drenagem paralela.

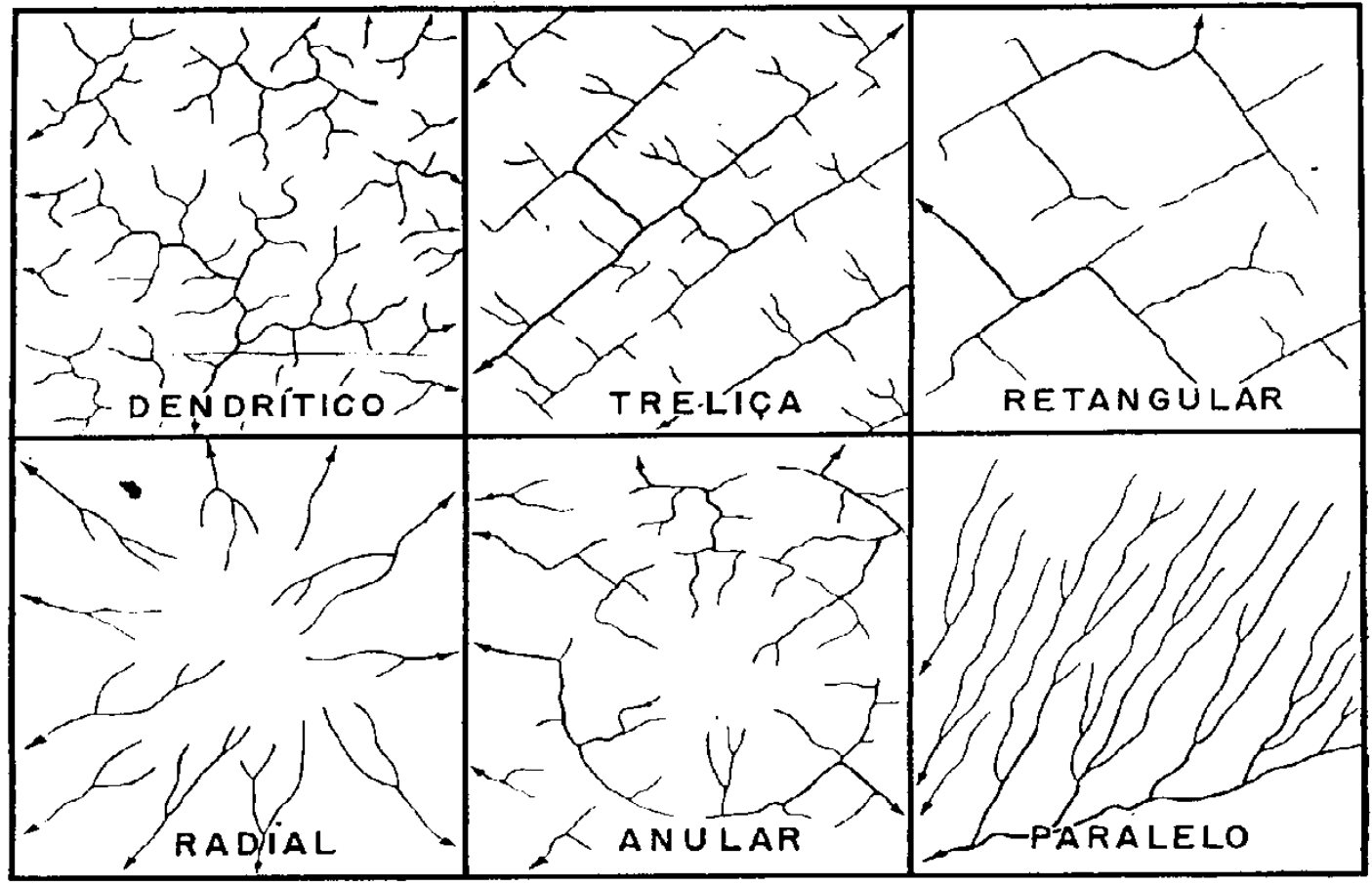

Figura 3 - Padrões de Drenagem, apresentação esquemática dos padrões de drenagem mais comuns. Segundo Morisawa apud Summerfield (1991), apud Lima (2006).

\section{Resultados e Discussões}

Os padrões de drenagens diferem ao arranjo espacial dos cursos d'água em um determinado meio físico, sendo influenciados principalmente pelas estruturas geológicas e climáticas que, assim, condicionam a uma dada geomorfologia local/regional.

O conhecimento dos fatores endógenos de uma determinada área é de grande importância para o entendimento das formas e padrões encontrados na superfície terrestre, assim a caracterização geológica (figura 5), mostra a alternância litológica, na qual as respostas são obtidas nos gráficos de perfis longitudinais e em alguns parâmetros

\footnotetext{
${ }^{2}$ Disponivel em http://www.webmapit.com.br/inpe/topodata/
} 
XVII Simpósio Brasileiro

de Geografia Fisica Aplicada

I Congresso Nacional

de Geografia Física

\section{OS DESAFIOS DA GEOGRAFIA FÍSICA NA FRONTEIRA DO CONHECIMENTO \\ Instituto de Geociências - Unicamp \\ Campinas - SP \\ 28 de Junho à 02 de Julho de 2017}

morfométricos, como hierarquia fluvial, padrão de drenagem, densidade de drenagem, entre outros.

Essa alternância é caracterizada pela passagem dos cursos d'água em rochas areníticas para basálticas, ou vice-versa, assim gerando formas e padrões que diferem na paisagem.

De acordo comHorton (1945) os padrões de drenagem são referidos como básicos e modificados, onde padrões básicos são aqueles em que suas propriedades são bem próprias e diferem fundamentalmente do outro padrão. Já o padrão de drenagem modificado é aquele com alguma variação das propriedades de um padrão básico.

As estruturas contidas em uma bacia hidrográfica e suas feições, lineamentos, alinhamentos estruturais e suturas (figura 4), também geram modificações na paisagem, que rebatem em diversas áreas gerando um padrão nas formas dos canais fluviais, no qual essas feições exercem influência na paisagem.

Nas Bacias Hidrográficas dos Rios Aguapeí e Peixe nota-se a influência de algumas dessas estruturas, chamadas por Etcheberehe et at. (2007), como megafeição estrutural de Presidente Prudente, a qual tem sua orientação a noroeste, influenciando assim os principais rios do oeste paulista (Rio Paranapanema, Rio do Peixe, Rio Aguapeí).

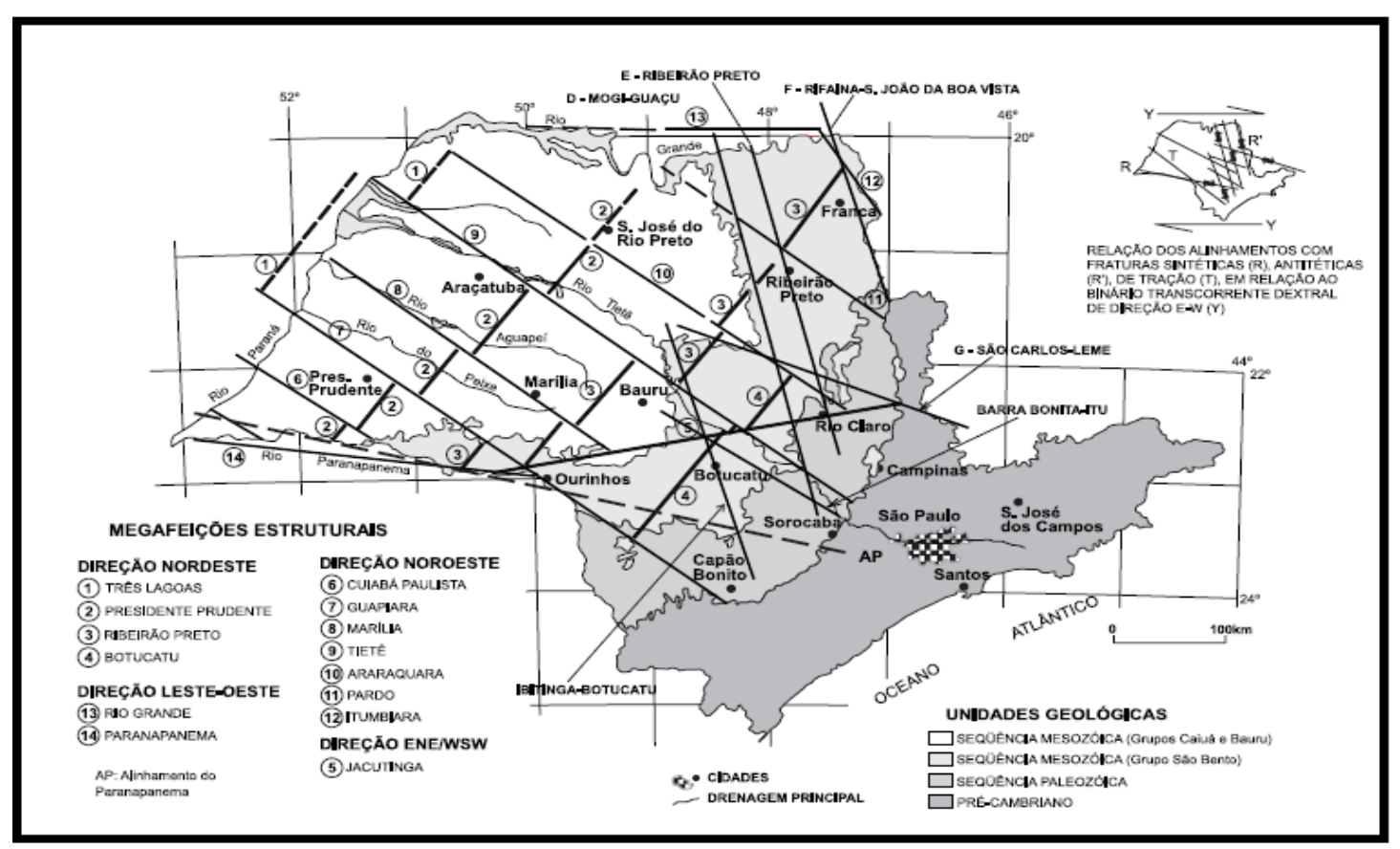

Figura 4 - Principais elementos estruturais da Bacia do Paraná no Estado de São Paulo. Fonte:Etchebehere et al (2007).

As bacias dos Rios Aguapeí e Peixe, localizadas no oeste do Estado de São Paulo identificam-se de uma maneira geral, com o padrão de drenagem dendrítico, porém, se analisadas em fragmentos na escala de 1:250.000, podem apresentar em suas sub-bacias características diferenciadas. 
A bacia hidrográfica do Rio Aguapeí apresenta na região de sua nascente um padrão sub-dendrítico, no qual ocorre uma mudança de configuração, passando a um padrão que se assemelha à drenagem paralela, indicando uma forte inclinação do terreno nesta área, principalmente em sua margem direita. Os rios tributários referidos anteriormente apresentam em suas cabeceiras de drenagens o padrão sub-dendrítico, característico de controles litológicos ou estruturais ${ }^{3}$, como descrito por Lima (2006).

A partir do médio curso do Rio Aguapeí, ocorre uma mudança no aspecto da drenagem, principalmente em relação à margem direita, apresentando um padrão dendrítico que em alguns casos pode ser confundido com o padrão treliça, contudo, por não configurar "ângulos retos", como condiz na literatura, esse trecho da bacia é mais bem descrito como padrão dendrítico.

Já na margem esquerda, existe um predomínio do padrão dendrítico, que em raras ocasiões alterna com o padrão paralelo, esboçando regiões com fortes declividades, nas quais as estruturas dos substratos orientam-se em relação à inclinação do terreno.

A Bacia Rio do Peixe apresenta em seu alto curso, mais precisamente junto à sua cabeceira de drenagem, um padrão que se assemelha com o paralelo, devido à forte inclinação do terreno, e, além disso, pela própria morfologia da região, caracterizada pelas escarpas da região da cidade de Marília exercendo grande influência na distribuição e na morfologia da drenagem.

Logo após o trecho referido acima, há certa intensificação da densidade de drenagem em ambas as margens do Rio do Peixe e em suas sub-bacias, surgindo drenagem com configurações dendríticas e sub-dendríticas, que em alguns casos oscilam com o padrão paralelo.

Já em seu médio curso, o padrão identificado configura-se em grande parte desse trecho, como padrão dendrítico, com recorrências de padrões sub-dendríticos e paralelos.

Um fato importante a se destacar deste trecho da bacia do Rio do Peixeé que há um aumento considerável da densidade de drenagem tornando o relevo desta área mais dissecado com uma grande concentração de drenagem. Isso pode ser explicado por um alinhamento estrutural localizado na região que faz com que o curso do Rio do Peixe mude a direção de seu

\footnotetext{
${ }^{3}$ Os controle litológicos e estruturais referem-se geometria e aos estudos dos corpos rochosos e da forma com que o a rocha reage frente a força dominante, no que tange a geométrica, cinemática e a dinâmica geológica. Ver Saad (1997) e Riccomini (1997). Etchebehere et al (2007) explana a respeito dos controles litológicos e estruturais, aquelas feições passivas, eventualmente resultantesde uma deformação pretérita, e sobre cuja geometria oscursos d'água podem se amoldar, fazendo com que o padrãolocal da rede de drenagem reflita a disposição dos corposrochosos, do arranjo e da atitude de seus estratose/ou de suas feições estruturais.
} 
XVII Simpósio Brasileiro de Geografia Fisica Aplicada

I Congresso Nacional de Geografia Física

\section{OS DESAFIOS DA GEOGRAFIA FÍSICA NA FRONTEIRA DO CONHECIMENTO \\ Instituto de Geociências - Unicamp \\ Campinas - SP \\ 28 de Junho à 02 de Julho de 2017}

curso de SE-NO, para NO-N, N-NO, NO-SO, SO-SE e assim seguindo com variações sutis de seu curso até a sua foz.

Nas regiões próximas à foz do rio do Peixe há uma mudança nos padrões de drenagem identificados e a diminuição da densidade de drenagem, passando a configurar padrões paralelos e sub-dendríticos. Assim, esse alinhamento estrutural exerce controle sobre a drenagem desse trecho da bacia hidrográfica do Rio do Peixe, que por consequência, acaba aumentando a densidade de drenagem.Diante disso, os padrões de drenagem de uma bacia hidrográfica ficam sob influência principalmente das formas estruturais como principal agente de causa e efeito.

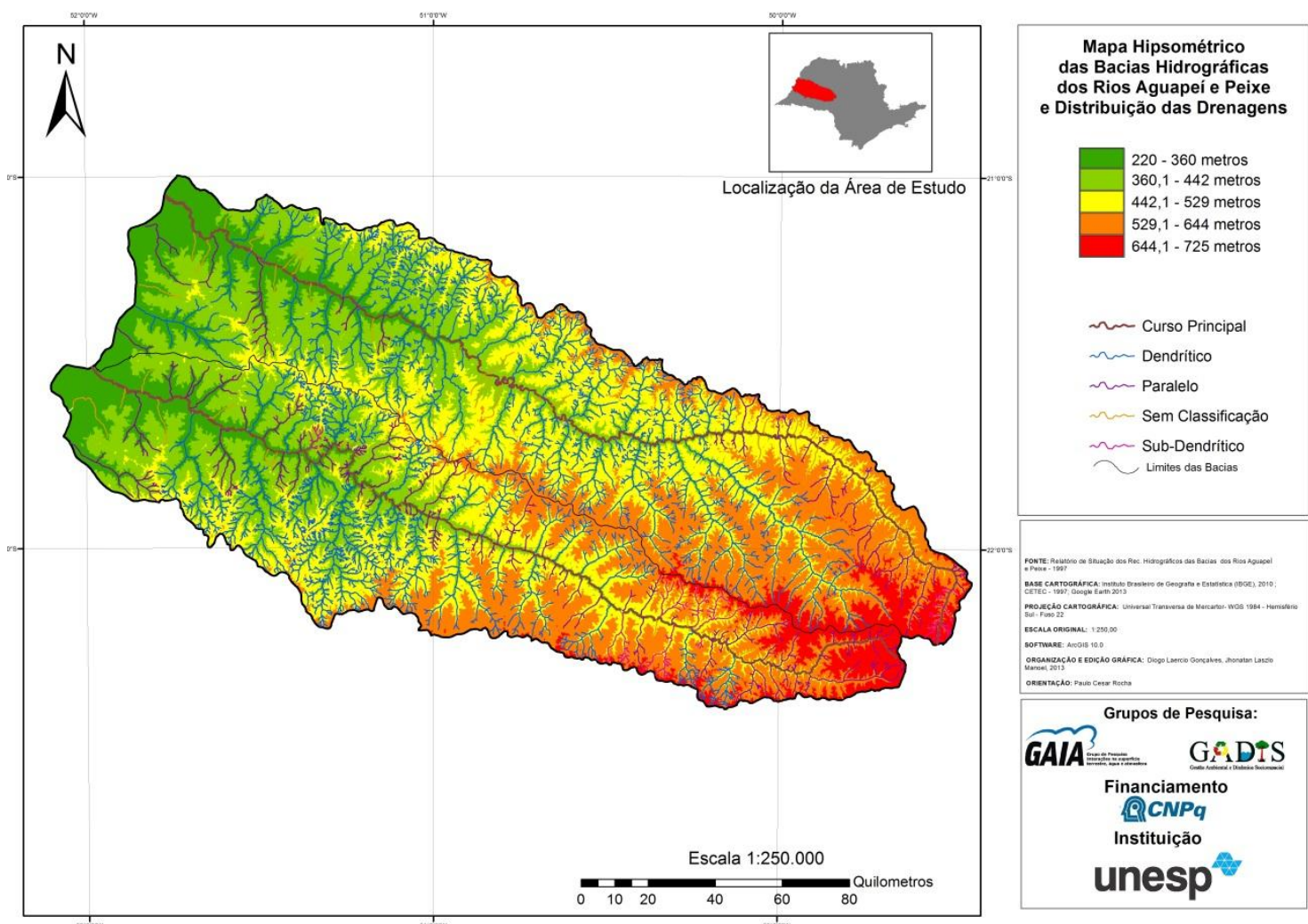

Figura 5 - Hipsometria em Conjunto com as Distribuições das Drenagens Identificadas nas Bacias Hidrográficas dos Rios Aguapeí e Peixe.

Existe um fator interessante a se destacar nas Bacias Hidrográficas do Rio Aguapeí e Peixe, que se encontra nas unidades da Formação Adamantina, mais precisamente na unidade Ka5 que se localiza principalmente nas bordas das bacias, mostrando uma distribuição mais abundante de canais fluviais e um padrão dendrítico mais denso, em relação a outros trechos da bacia $^{4}$

${ }^{4}$ No sudoeste da Bacia Hidrográfica do Rio do Peixe, se localize a bacia hidrográfica do Ribeirão Mandaguari, que comporta a maior densidade de drenagem de toda a Bacia do Rio do Peixe, e também contém o maior índice de hierarquia fluvial (Laszlo 2014 e Laszlo 2016).no qual a Bacia do 

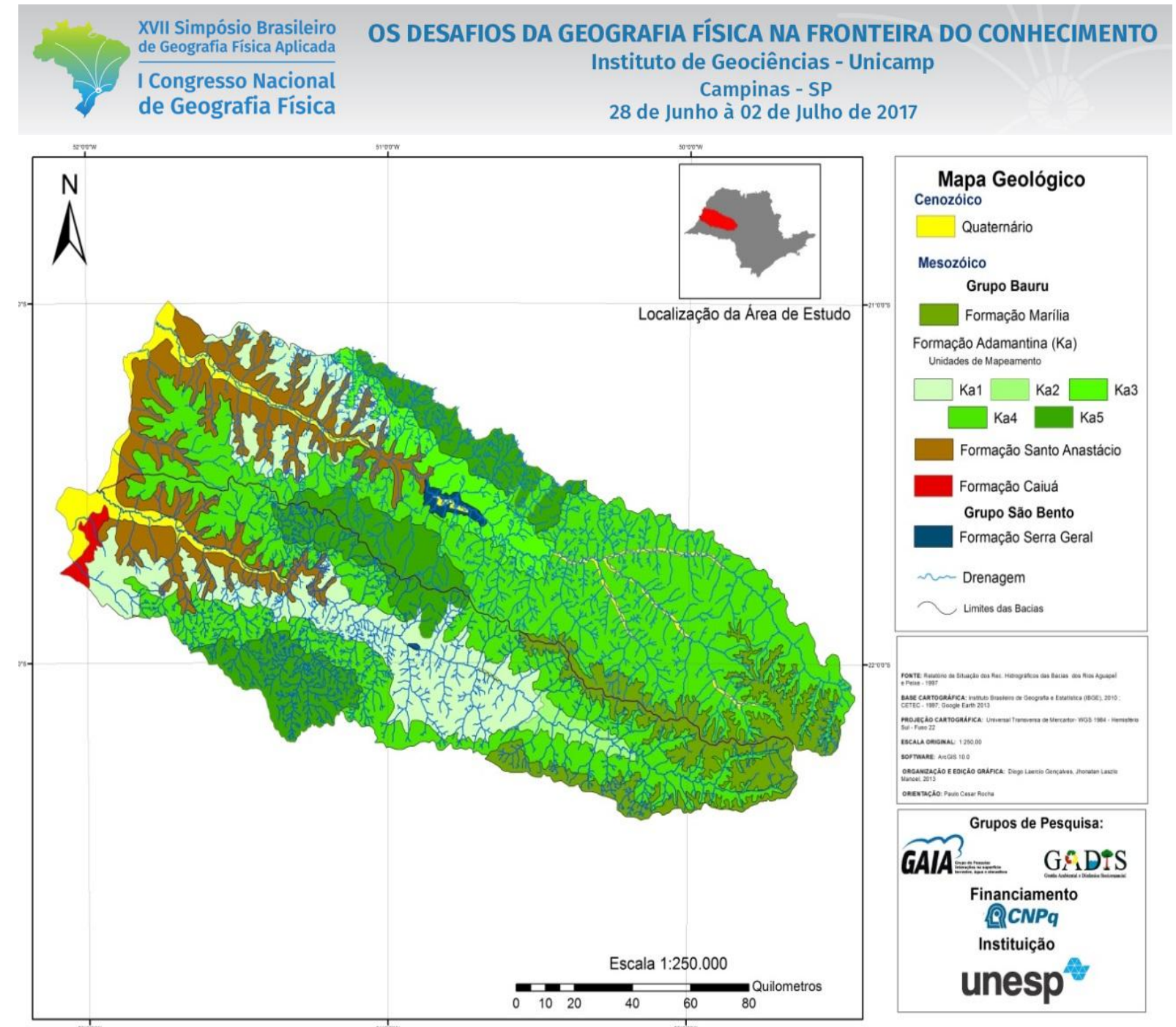

Figura 6 - Mapa Geológico das Bacias Hidrográficas dos Rios Aguapeí e Peixe.

Por fim, existem canais que não foram classificados pelo devido fato de não conterem tributários e confluindo diretamente com o curso principal, e assim, não esboçando nenhuma configuração genética, com apenas um canal retilíneo.

\section{Conclusão}

As alterações da forma da ocorrência e apresentação da configuração dos padrões de drenagem estão fortemente vinculadas as variações litológicas (resistência das rochas), declividade do terreno, uso e ocupação do solo, grau deresistência a erosões, etc.

Entrando um pouco no mérito das relações dos processos e dinâmicas endógenas e exógenas, a densidade de drenagem contém uma relação intrínseca com os processos endógenos, ou seja, sendo determinados justamente por variações geológico-litológicas de uma determinada área, porém, ainda assim, sofrendo as influências dos fenômenos externos, como as oscilações climáticas e do próprio homem.

Ribeirão Mandaguari abarca uma dinâmica diferenciada das outras demais sub-bacias que englobam a Bacia do Rio do Peixe (Ver Baumgardner 1979). 
Contudo, os padrões de drenagem se apresentam em relação às estruturas geológicas provenientes de seu substrato, assim como o predomínio da Formação Adamantina nas Bacias dos Rios Aguapeí e Peixe traz consigo poucas variações nos padrões de drenagem da área de estudo, mesmo contendo cinco unidades de mapeamento, que apresentam certas características diferenciadas. Com isso, cria-se uma resistência uniforme, que faz com que haja um predomínio do padrão de drenagem dendrítico.

\section{Referências}

CUNHA. S. B. Geomorfologia fluvial p. 225. In: GUERRA, Antonio José Teixeira; CUNHA, Sandra Baptista da (org.). Geomorfologia: uma atualização de bases e conceitos. 4. ed. Rio de Janeiro: Bertrand Brasil, 2001, 472 p.

CHRISTOFOLETTI, A. Geomorfologia - São Paulo: Edgard Blucher: EDUSP, 1974, 149 p.

CHRISTOFOLETTI, A. Geomorfologia fluvial - São Paulo: Edgard Blucher: FAPESP, 1981, 313 p.

HORTON, R. E. Erosional development of streams and their drainage basin: hidrophysicalapprouch to quantitative morphology, Geol. Soc. AmericaBulletin, 1945, 56 (3), pp. 275-370

HOWARD, A.D. Drainage analysis in geologic interpretation: summation. Bulletin American Association of Petroleum Geologists, Tulsa, v.5, n.11, p.2246-2259, 1967.

LIMA, M. I. C. Análise de drenagem e seu significado geológico-geomorfológico, Belém, Pará, UFPA, 2006, 222.

PENTEADO, M. M. Fundamentos de geomorfologia/Margarida Maria Penteado. - Rio de Janeiro: IBGE, $1974141 \mathrm{p}$.

Relatório de Situação dos Recursos Hídricos das Bacias dos Rios Aguapeí e Peixe - 1997.

SUGUIO, K.; BIGARELLA, J.J. Ambientes fluviais. 2.ed. Florianópolis: UFSC, 1990. 183p.

RICCOMINI, C. Arcabouço estrutural e aspectos do tectonismo gerador e deformador da Bacia Bauru no Estado de São Paulo. Revista Brasileira de Geociências, v. 27, n. 2, p. 153-162, 1997.

SAAD, A. R. Análise da produção técnico-científica. 1997.150 f. Instituto de Geociências e Ciências Exatas,Universidade Estadual Paulista, Rio Claro. 